\title{
Metode Elemen Hingga Untuk Perpindahan Panas Konduksi Steady State pada Domain 2D dengan Menggunakan Elemen Segitiga
}

\author{
Surya Ningsih \\ Universitas Sembilanbelas November Kolaka \\ e-mail: sningsih993@gmail.com
}

\begin{abstract}
Abstrak
Perpindahan panas konduksi adalah perpindahan panas antar molekul tanpa disertai pergerakan aktual dari molekul tersebut. Tujuan utama dari analisis konduksi adalah menentukan distribusi temperatur pada medium, baik pada kasus tunak (steady state) maupun tak tunak (bergantung waktu atau transient). Salah satu metode yang dapat digunakan untuk menyelesaikan persoalan tersebut adalah metode elemen hingga (finite element method atau FEM). Dengan metode pendekatan ini akan membentuk persamaanpersamaan numerik yang harus diselesaikan dengan cermat dan teliti untuk memperoleh hasil yang akurasi. Untuk mendapatkan hasil yang lebih baik dan akurasi, maka domain akan dibagi dalam beberapa bagian elemen dimana dalam setiap sudut garis elemen akan terdapat node/simpul pada jarak tertentu. Semakin banyak elemen pada sebuah benda yang dianalisis, maka tingkat akurasinya semakin bagus. Persoalan akan menjadi lebih sulit jika diselesaikan secara manual dalam penyelesaian numeriknya. Oleh karena itu, dalam tulisan ini penyelesaian metode numerik tersebut akan diselesaikan dengan menggunakan software MATLAB. Hasil dari pemodelannya adalah distribusi temperatur. Konduktivitas panas juga divariasikan untuk mengetahui hubungan antara distribusi temperatur dengan konduktivitas panas bahan..
\end{abstract}

Kata Kunci: Elemen Segitiga, Perpindahan Panas Konduksi 2D, Kondisi Steady State, FEM

\section{PENDAHULUAN}

Perpindahan panas dapat terjadi dalam tiga cara, yaitu: konduksi, konveksi, dan radiasi. Namun pada tulisan ini hanya membahas perpindahan secara konduksi. Perpindahan panas atau disebut juga distribusi panas adalah proses berpindahnya panas dari benda yang mempunyai suhu tinggi ke suhu lebih rendah. Salah satu jenis perpindahan panas adalah konduksi yang merupakan suatu proses yang jika dua benda suhunya disentuhkan dengan yang lainnya maka akan terjadilah perpindahan panas (Kreith, 2005) (Yunus, 2009).

Perpindahan panas secara konduksi adalah ketika energi berpindah karena adanya getaran molekul pada batuan. Perpindahan panas yang terjadi di dalam bumi merupakan persoalan kompleks karena melibatkan banyak parameter dan bersifat inhomogen dan anisotropi. Sehingga penyelesaian persoalan perpindahan panas dalam bumi memerlukan asumsi asumsi untuk menyederhanakan permasalahan. Untuk masalah yang kompleks dapat dikerjakan dengan menggunakan metode numerik. Salah satu metode numerik yang dapat digunakan adalah Metode Elemen Hingga (Finite Element Method). Metode elemen hingga adalah salah satu metode numerik yang dapat digunakan untuk menyelesaikan persoalan syarat batas yang diatur oleh persamaan diferensial dan suatu syarat batas (Katili, 2006). Ide utama dalam metode elemen hingga adalah membagi geometri domain dari permasalahan menjadi sub-sub domain yang lebih kecil atau sering disebut sebagai elemen hingga. Bentuk elemen yang sering digunakan adalah elemen segitiga dan quadrilateral. Pada tulisan ini Penulis melakukan perhitungan solusi permasalahan syarat batas dengan menggunakan metode elemen hingga pendekatan Galerkin. Metode elemen hingga diterapkan pada persamaan perpindahan panas konduksi dengan solusi berupa distribusi temperatur pada domain 2 dimensi.

Functionally Graded Materials (FGMs). Functionally Graded Materials (FGMs) adalah kelas material maju dari material komposit yang memiliki sifat material yang bervariasi dari satu titik ke titik

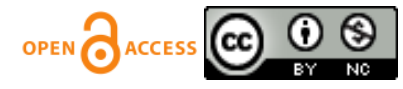


lainnya (Mas Irfan, 2014). Dalam literatur lain, FGMs adalah material yang dalamnya terdapat beberapa sifat fisik particular yang berubah ditiap dimensi (El-Wazery dan El-Desouky, 2015). Dengan demikian, FGMs memiliki gradient komposisional dari satu komponen ke komponen lainnya. Karakteristik sifat material yang kontinyu tersebut menghilangkan masalah-masalah terkait diskontinyuitas interface yang lazim dijumpai di material komposit biasa, sehingga FGMs dapat didesain berdasarkan fungsi tertentu yang dikehendaki. FGMs juga dapat dikembangkan menggunakan fiber-reinforced dengan fraksi volume serat secara konstanta, dengan memperhatikan produksi sifat set optimal atau respon (Birman, 1995; Birman, 1997).

\section{METODE PENELITIAN}

Dalam penulisan ini, metode penelitian yang digunakan yaitu :

1. Mengumpulkan data dan informasi mengenai materi terkait melalui studi kepustakaan

2. Menggunakan metode elemen hingga untuk mendapatkan solusi yang terkait dengan menggunakan program MATLAB. Metode ini digunakan untuk menyelesaikan persamaan parsial dengan membagi setiap sistem menjadi elemen-elemen dengan geometri tertentu. Dari elemen-elemen tersebut akan tersusun matriks persamaan linear. Dalam proses penyelesaian elemen hingga diperlukan elemen dengan geometri tertentu beserta fungsi bentuk atau shape function, yang mempresentasikan ciri solusi dari setiap elemen. Dalam penelitian ini digunakan elemen segitiga (2-D) dengan fungsi bentuk linear.

3. Elemen Segitiga linier

pada elemen segitiga, interpolasi linear untuk aproksimasi fungsi tertentu dapat dinyatakan sebagai berikut (Zienkiewick dkk., 2005);

$u(x, y)=\alpha_{1}+\alpha_{2} x+\alpha_{3} y$

Pada gambar 1, nilai $T$ pada masing-masing titik adalah:

$T_{i}=\alpha_{1}+\alpha_{2} x_{i}+\alpha_{3} y_{i}$

$T_{j}=\alpha_{1}+\alpha_{2} x_{j}+\alpha_{3} y_{j}$

$T_{k}=\alpha_{1}+\alpha_{2} x_{k}+\alpha_{3} y_{k}$

Yang menghasilkan koefisien-koefisien

$$
\begin{aligned}
& \alpha_{1}=\frac{1}{2 A}\left[\left(x_{j} y_{k}-x_{k} y_{j}\right) u_{i}+\left(x_{k} y_{i}-x_{i} y_{k}\right) u_{j}+\left(x_{i} y_{j}-x_{j} y_{i}\right) u_{k}\right] \\
& \alpha_{2}=\frac{1}{2 A}\left[\left(y_{j}-y_{k}\right) u_{i}+\left(y_{k}-y_{i}\right) u_{j}+\left(y_{i}-y_{j}\right) u_{k}\right] \\
& \alpha_{3}=\frac{1}{2 A}\left[\left(x_{k}-x_{j}\right) u_{i}+\left(x_{i}-x_{k}\right) u_{j}+\left(x_{j}-x_{i}\right) u_{k}\right]
\end{aligned}
$$

dengan $A$ adalah luas elemen segitiga.

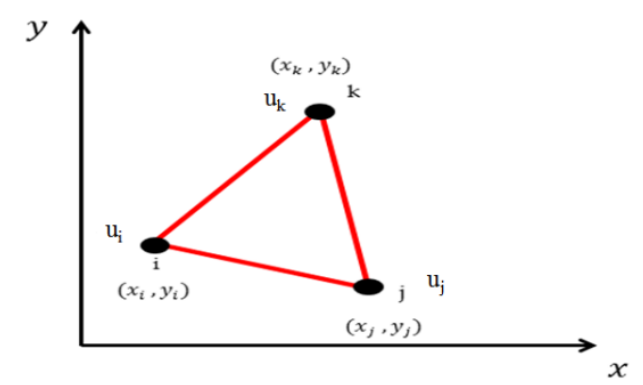

Gambar 1. Elemen Segitiga 
Dengan mensubstitusikan $\alpha_{1}, \alpha_{2}$, dan $\alpha_{3}$ akan diperoleh fungsi bentuk untuk elemen segitiga.

$T=N_{i} T_{i}+N_{j} T_{j}+N_{k} T_{k}=\left[\begin{array}{lll}N_{i} & N_{j} & N_{k}\end{array}\left[\begin{array}{l}T_{i} \\ T_{j} \\ T_{k}\end{array}\right]\right.$

dimana

$N_{i}=\frac{1}{2 A}\left(a_{i}+b_{i} x+c_{i} y\right)$

$N_{j}=\frac{1}{2 A}\left(a_{j}+b_{j} x+c_{j} y\right)$

$N_{k}=\frac{1}{2 A}\left(a_{k}+b_{k} x+c_{k} y\right)$

dan

$a_{i}=x_{j} y_{k}-x_{k} y_{j} \quad b_{i}=y_{j}-y_{k} c_{i}=x_{k}-x_{j}$

$a_{j}=x_{k} y_{i}-x_{i} y_{k} \quad b_{j}=y_{k}-y_{i} c_{j}=x_{i}-x_{k}$

$a_{k}=x_{i} y_{j}-x_{j} y_{i} \quad b_{k}=y_{i}-y_{j} c_{k}=x_{j}-x_{i}$

Metode residual adalah metode aproksimasi untuk menyelesaikan persamaan differensial dengan memberikan nilai bobot pada residual atau sisa dari persamaan aproksimasi (zienkiewicz dkk., 2005). Formulasi Galerkin digunakan agar residual menjadi minimal dengan mengalikan integrasi residual dengan suatu fungsi bobot $w_{i}(x)$;

$\int_{\Omega} w_{i}(x) R(x) d x=0$

Fungsi bobot diganti dengan fungsi bantu atau shape function dari metode elemen hingga yang digunakan sebagai aproksimasi. Dengan meninjau persamaan kecepatan aliran fluida dan persamaan perpindahan panas konduksi-konveksi pada keadaan tunak serta menerapkan metode residual dan syarat batas Neumann maka diperoleh:

$$
\begin{aligned}
& K_{i j}^{e}=\iint_{\Omega} N_{i} \rho C_{p}\left[u_{x} \frac{\partial N_{j}}{\partial x}+u_{y} \frac{\partial N_{j}}{\partial y}\right] d x d y \\
& +\left\{-\iint_{\Omega^{e}}\left[k_{x} \frac{\partial N_{i}}{\partial x}+k_{y} \frac{\partial N_{j}}{\partial y}\right] d x d y\right\} \\
& f_{i}^{e}=\iint_{\Omega^{e}} N_{i} Q d x d y \\
& p_{i}^{e}=\oint_{\Gamma^{e}} N_{i}\left(k_{x} \frac{\partial T}{\partial x} n_{x}+k_{y} \frac{\partial T}{\partial y} n_{y}\right) d l
\end{aligned}
$$

\section{HASIL DAN PEMBAHASAN}

\subsection{Pemodelan Pada Plat}

Pada pemodelan ini menggunakan domain persegi panjang yang memiliki panjang $\mathrm{x}$ pada arah horizontal dan kedalaman y pada arah vertikal. Adapun bentuk domainnya sebagai berikut: 


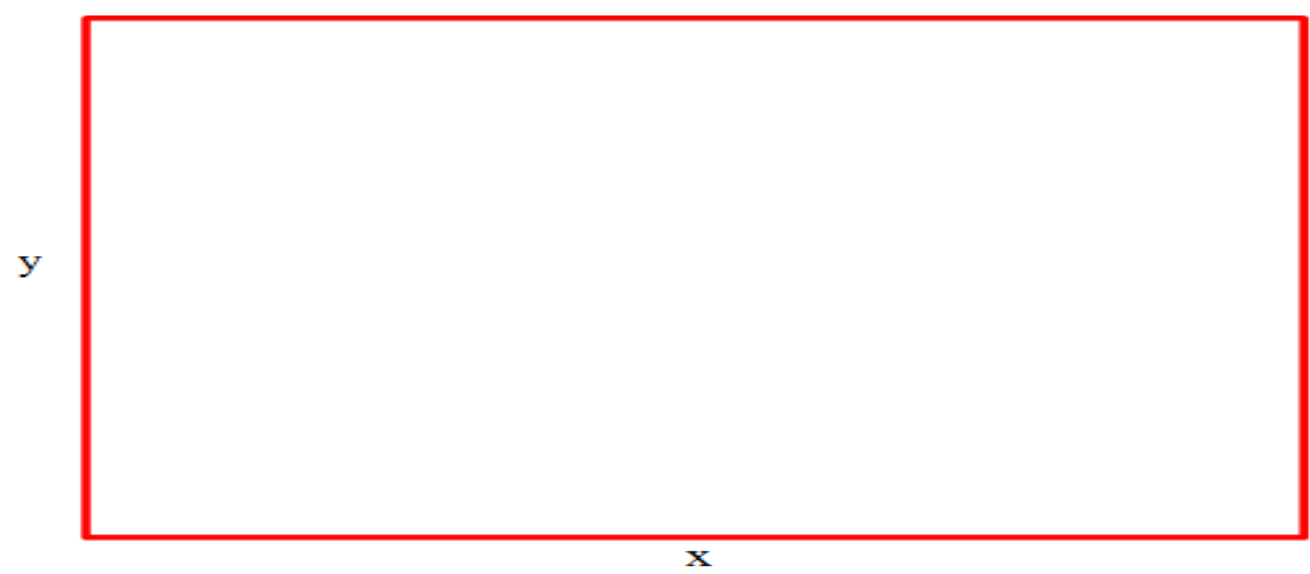

Gambar 1. Bentuk domain persegi panjang

Domain ini kemudian di diskritisasi dengan elemen persegi empat sebanyak 20000 elemen dan setiap elemen persegi empat dibagi menjadi dua elemen segitiga seperti yang ditunjukkan. Untuk mencari kecepatan aliran fluida domain dikenakan syarat batas Neumann di semua sisi. Untuk arah aliran dari kiri ke kanan domain batas sisi kiri diberi nilai $\mathrm{q}_{\text {in }}=30 \mathrm{~m} / \mathrm{s}$ dan domain batas sisi kanan diberi nilai $\mathrm{q}_{\text {out }}=-30 \mathrm{~m} / \mathrm{s}$, sedangkan batas sisi atas dan bawah diberi nilai $\mathrm{q}=0$. Untuk arah aliran dari bawah ke atas domain batas sisi bawah diberi nilai $\mathrm{q}_{\mathrm{in}}=30 \mathrm{~m} / \mathrm{s}$ Domain pada sisi kiri diberi nilai temperatur sebesar $200{ }^{\circ} \mathrm{C}$, sisi bagian bawah diberi nilai temperatur sebesar $150{ }^{\circ} \mathrm{C}$, sedangkan sisi kanan dan atas diberi nilai $q=0$ (isolator). Setiap elemen kemudian diberikan nilai konduktivitas. Distribusi temperatur kemudian dihitung dengan menggunakan metode elemen hingga seperti yang telah dijelaskan pada bab sebelumnya.

\subsection{Syarat Batas Model}

Untuk memperoleh solusi dari metode elemen hingga untuk model ini diperlukan syarat batas pada bagian batas luar domain. Diasumsikan tidak ada panas yang keluar dari sisi kanan dan sisi atas pada domain, sehingga syarat batas yang diberlakukan untuk bagian sisi kanan dan sisi atas adalah syarat batas neumann:

$$
\left.\frac{\partial T}{\partial n}\right|_{\Gamma}=0
$$

Sedangkan pada sisi kiri dan sisi kanan diberlakukan syarat batas Dirichlet:

$$
\left.T\right|_{\Gamma}=T_{0}
$$

\subsection{Hasil Pemodelan untuk Domain dengan Konduktivitas Homogen}

Pemodelan distribusi temperatur dilakukan dengan menggunakan metode elemen hingga. Hasilnya berupa nilai temperatur pada titik simpul elemen segitiga yang tersebar di dalam domain. Berikut ini hasil pemodelan distribusi temperatur pada medium dengan konduktivitas panas homogen. 
https://jurnal.unsulbar.ac.id/index.php/saintifik

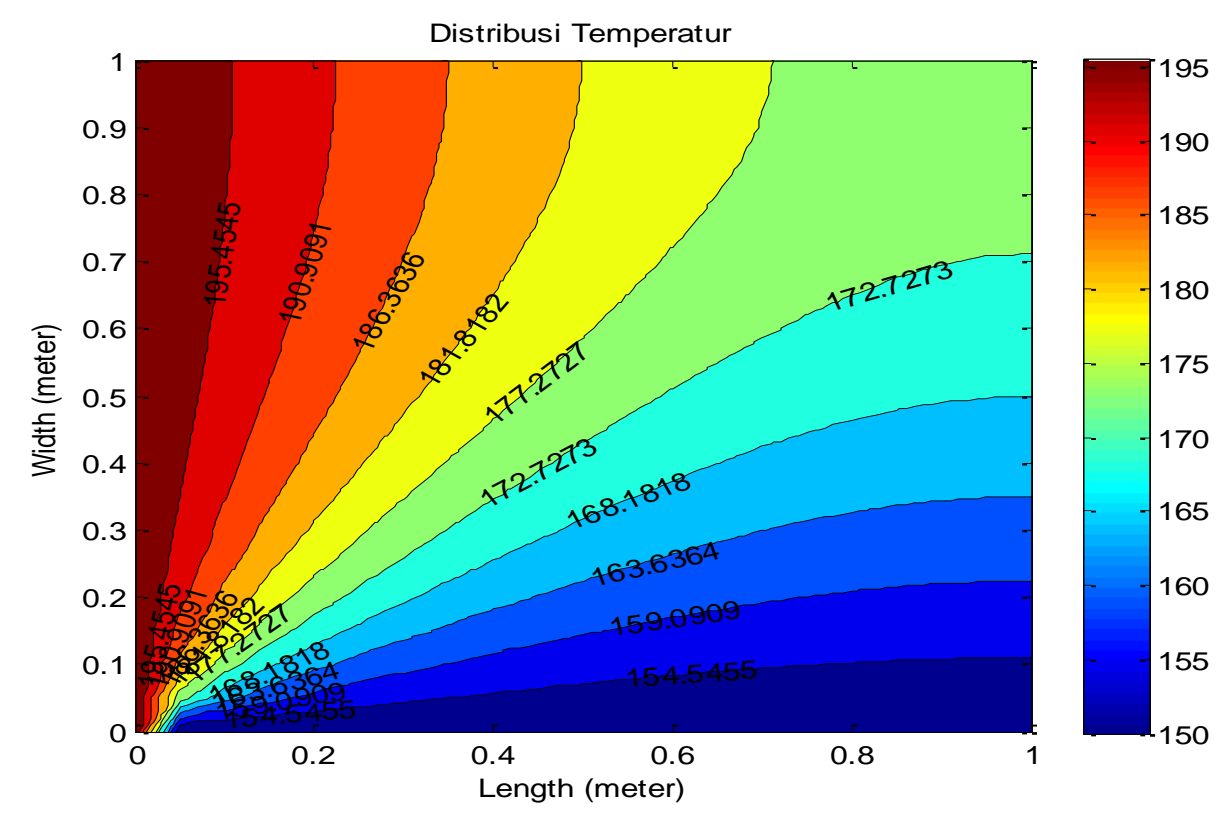

Gambar 2. Hasil pemodelan distribusi temperatur 2D homogen tanpa $\mathrm{G}$ dengan konduktivitas panas 40 $\mathrm{W} / \mathrm{m} .{ }^{0} \mathrm{C}$.

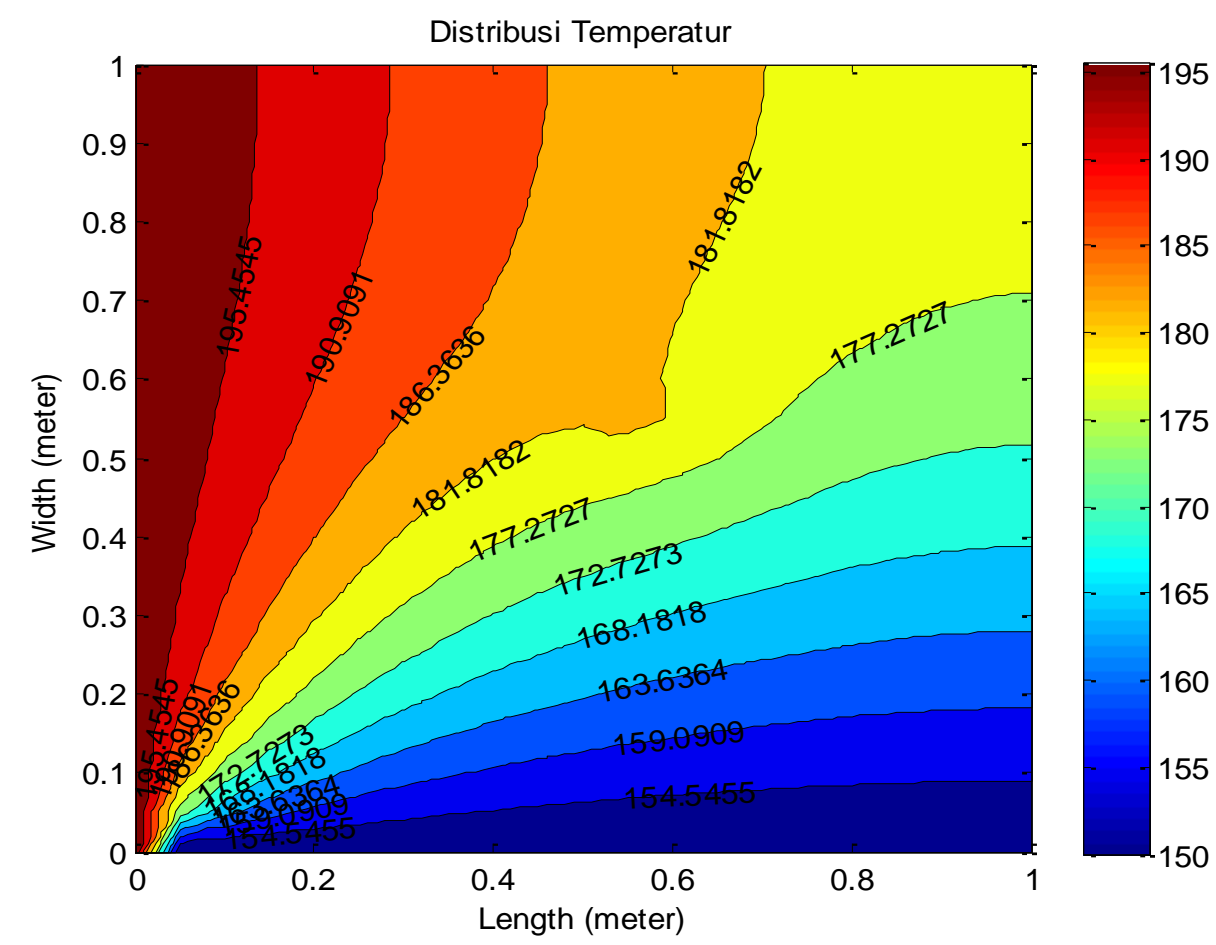

Gambar 3. Hasil pemodelan distribusi temperatur 2D homogen yang diberi G dengan konduktivitas panas 40 $\mathrm{W} / \mathrm{m}^{0} \mathrm{C}$. 
https://jurnal.unsulbar.ac.id/index.php/saintifik

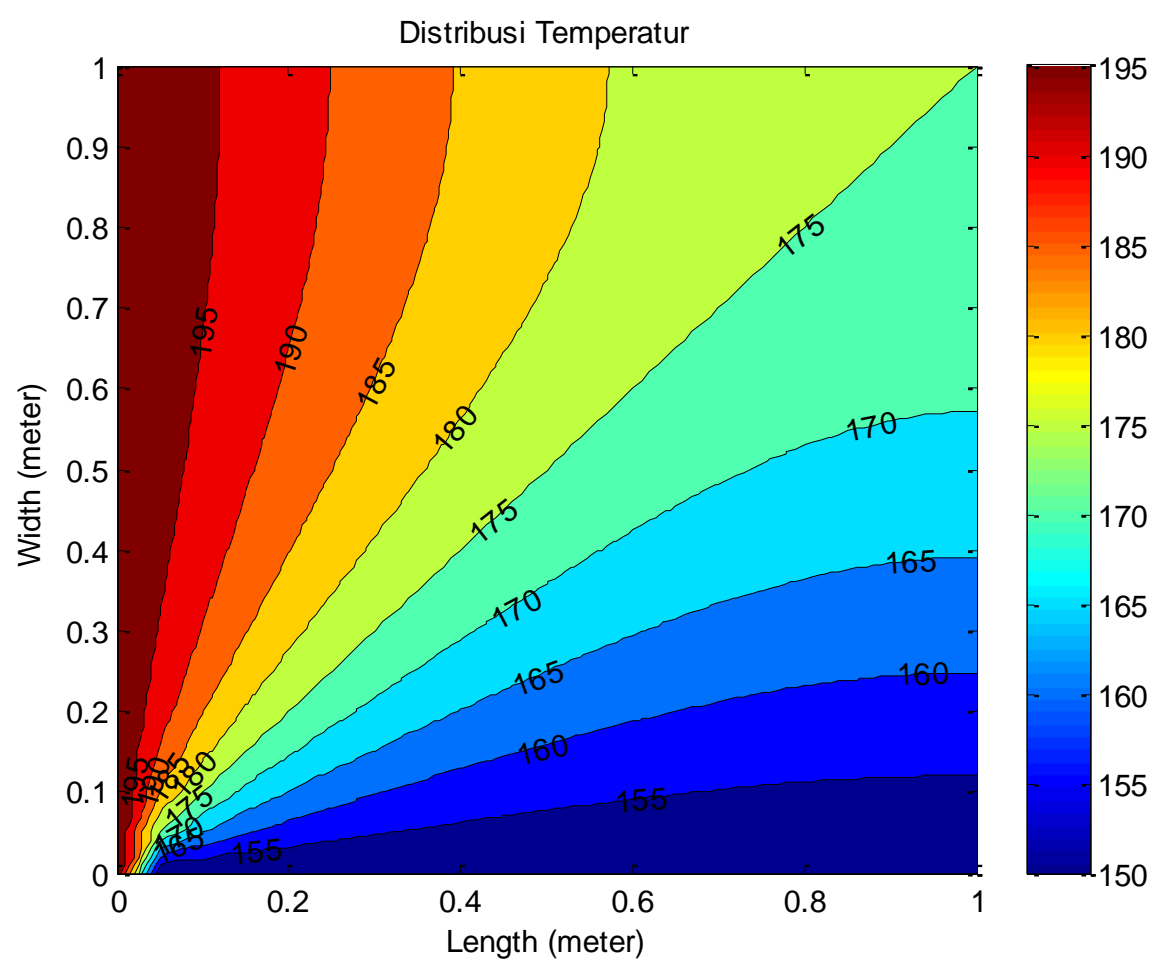

Gambar 4. Hasil pemodelan distribusi temperatur 2D homogen tanpa diberi G dengan konduktivitas panas $380 \mathrm{~W} / \mathrm{m}^{0} \mathrm{C}$.

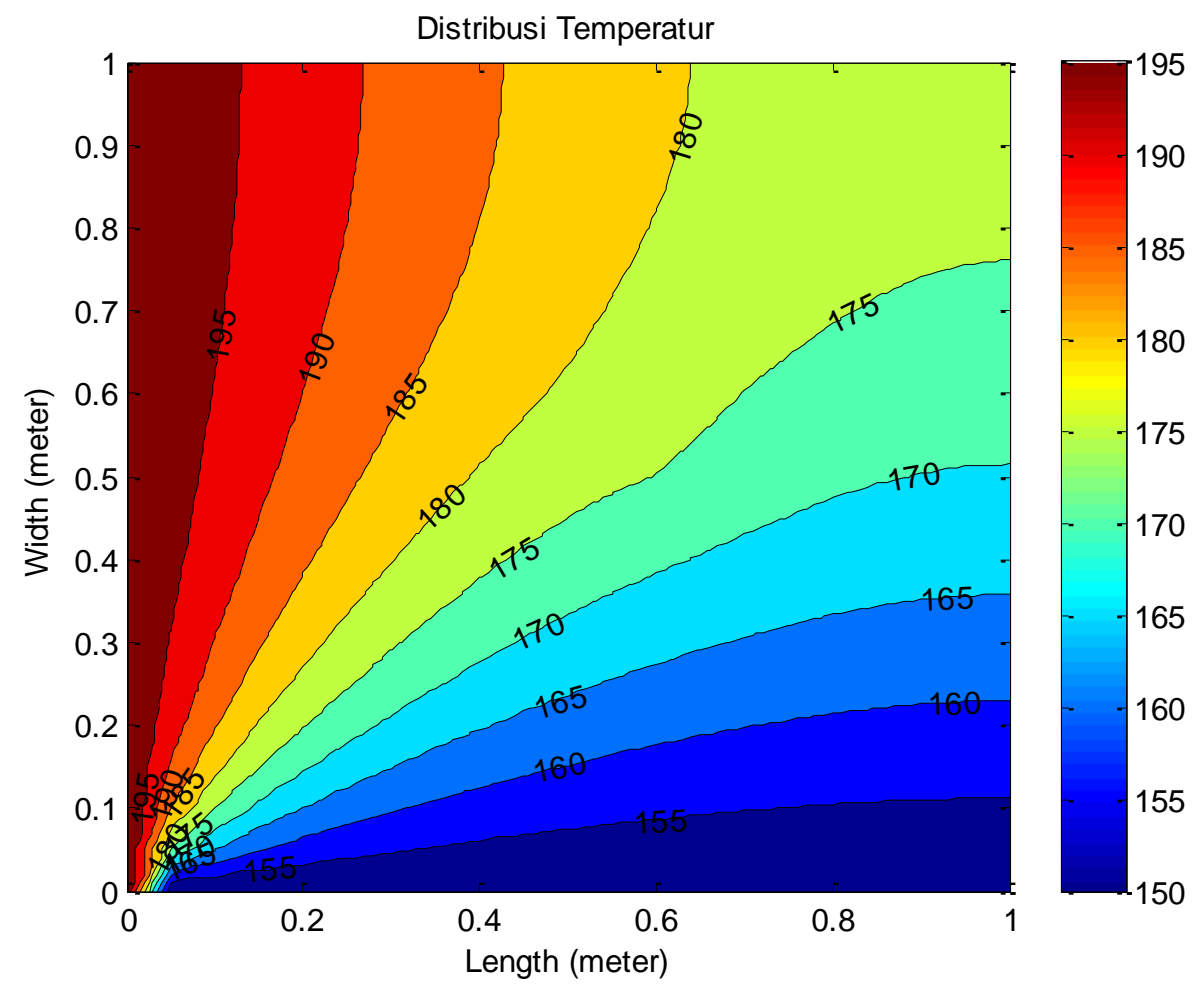

Gambar 5. Hasil pemodelan distribusi temperatur 2D homogen dengan diberi G dengan konduktivitas panas $380 \mathrm{~W} / \mathrm{m}^{0} \mathrm{C}$ 
https://jurnal.unsulbar.ac.id/index.php/saintifik

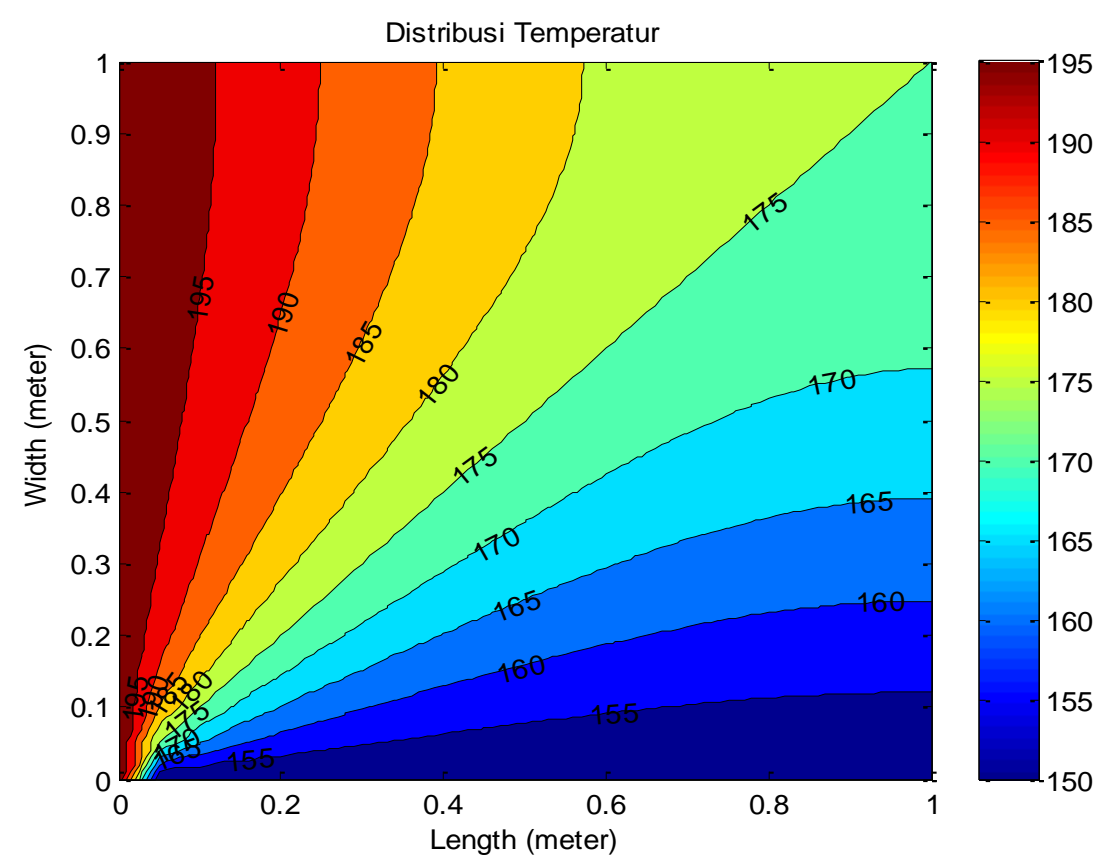

Gambar 6. Hasil pemodelan distribusi temperatur 2D homogen tanpa diberi G dengan konduktivitas panas $420 \mathrm{~W} / \mathrm{m}^{0} \mathrm{C}$

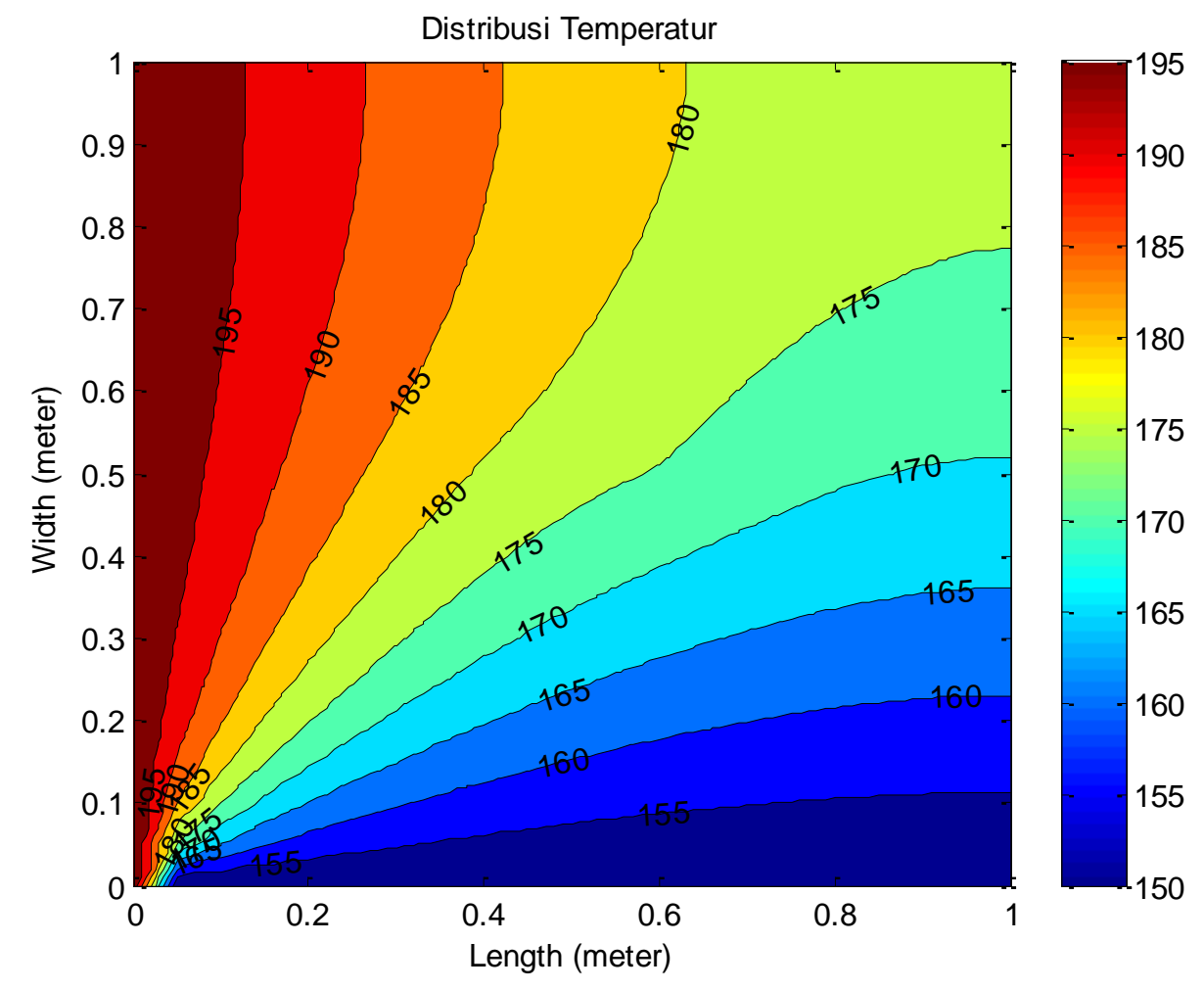

Gambar 7. Hasil pemodelan distribusi temperatur 2D homogen dengan diberi G dengan konduktivitas panas $420 \mathrm{~W} / \mathrm{m}^{0} \mathrm{C}$ 


\section{https://jurnal.unsulbar.ac.id/index.php/saintifik}

Dapat terlihat perbedaan pada gambar diatas, bahwa pada Gambar yang dikarenakan adanya sumber panas sebesar $320 \mathrm{~W} / \mathrm{m}^{3}$, menyebabkan distribusi temperatur meningkat dibandingkan pada Gambar dengan distribusi temperatur pada plat tanpa sumber panas. Dapat terlihat juga bahwa semakin besar konduktivitas termal maka distribusi temperatur akan semakin kecil. Pernyataan ini sesuai dengan hukum Fourier tentang konduksi panas.

\subsection{Hasil pemodelan pada domain dengan dua nilai konduktivitas panas dengan 2 nilai yang berbeda}

Pemodelan distribusi pada plat campuran dengan dua nilai konduktivitas panas yang berbeda. Berikut ini gambar model dan hasil kontur distribusi temperatur.

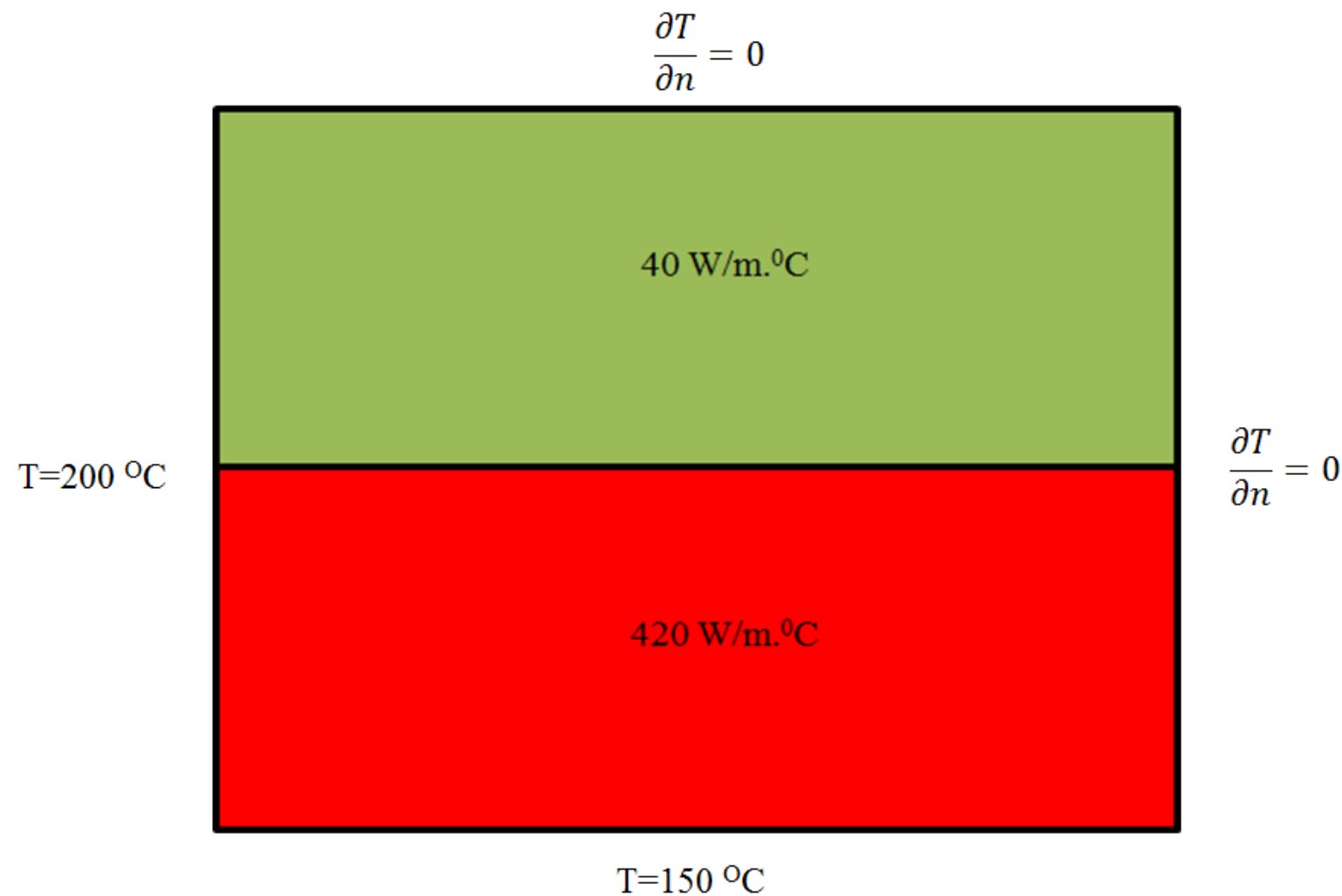

Gambar 8. Plat campuran baja dan perak dengan konduktivitas panas $40 \mathrm{~W} / \mathrm{m} .{ }^{0} \mathrm{C}$ dan $420 \mathrm{~W} / \mathrm{m} .{ }^{0} \mathrm{C}$. 
https://jurnal.unsulbar.ac.id/index.php/saintifik

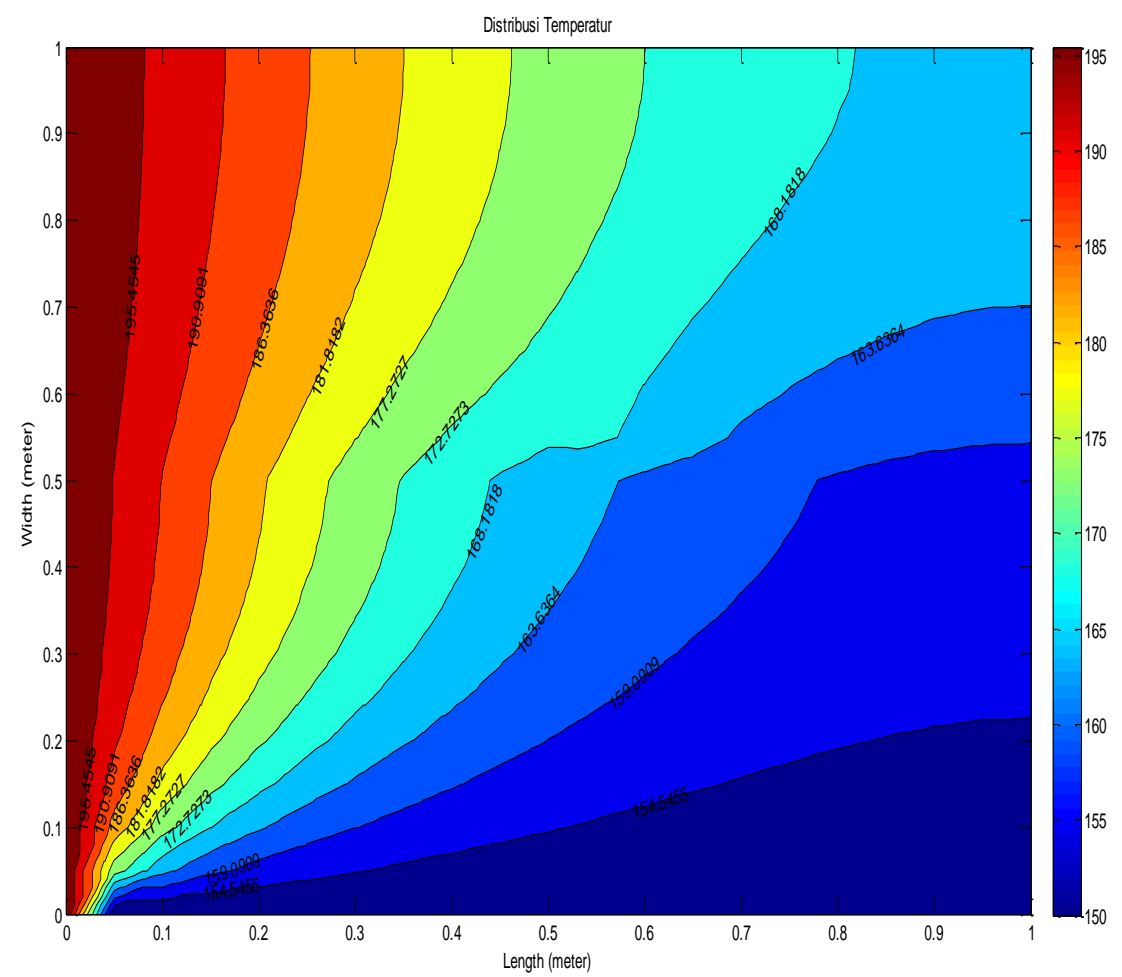

Gambar 9. kontur distribusi temperatur pada plat campuran tanpa nilai $\mathrm{G}$

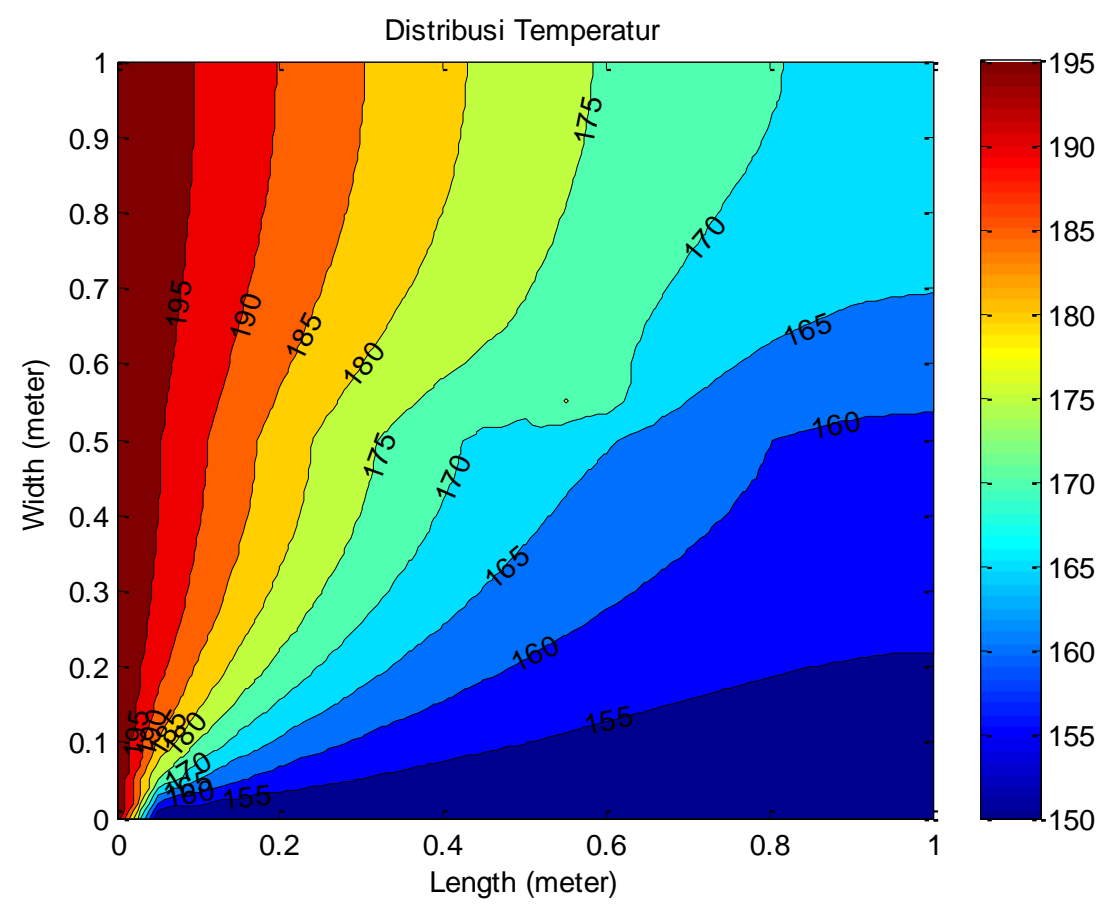

Gambar 10. kontur distribusi temperatur pada plat campuran dengan nilai G 
https://jurnal.unsulbar.ac.id/index.php/saintifik

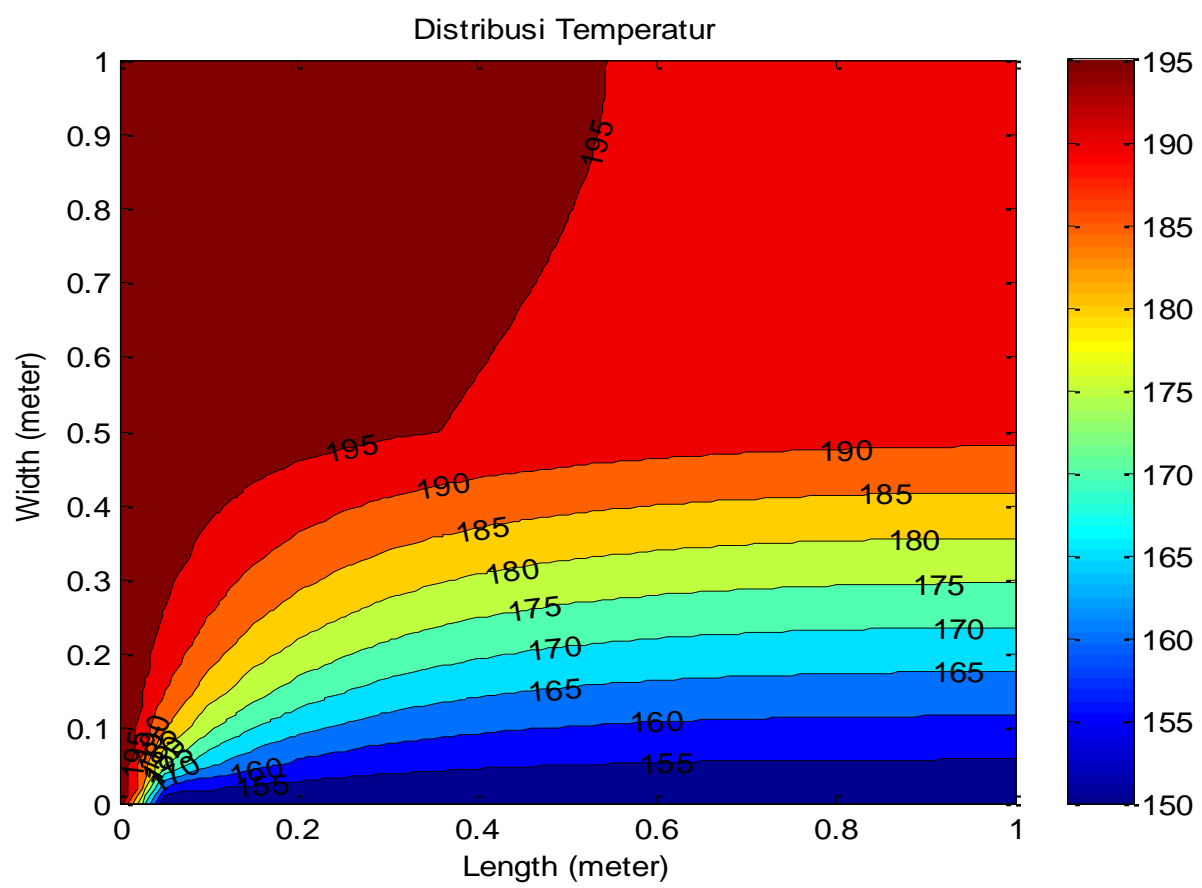

Gambar 11. Kontur distribusi temperatur pada plat berlapis tanpa nilai $\mathrm{G}(\mathrm{L} 1=420, \mathrm{~L} 2=40)$.

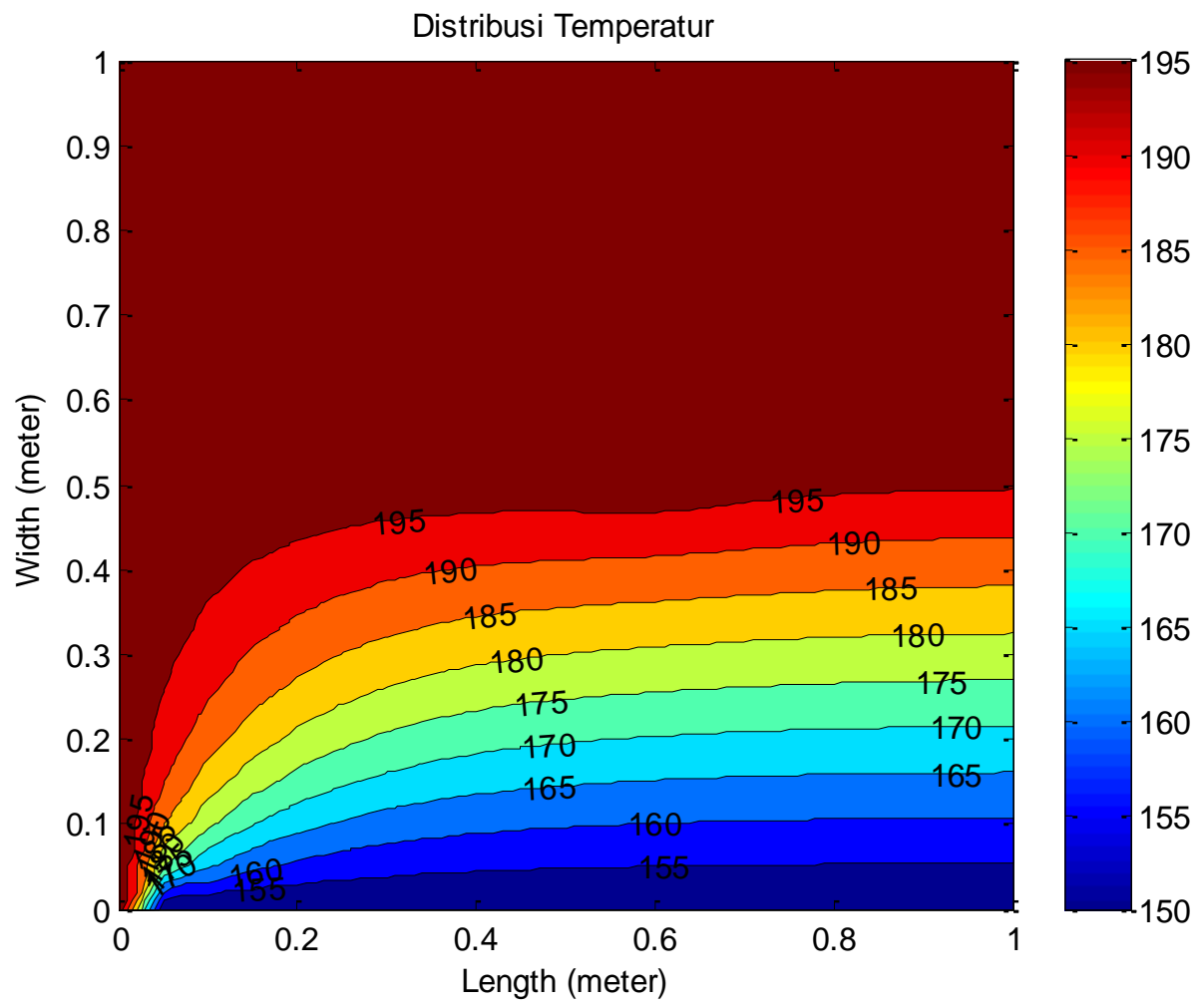

Gambar 12. Kontur distribusi temperatur pada plat berlapis dengan nilai $G(L 1=420, L 2=40)$.

Pada plat berlapis diatas dapat disimpulkan bahwa distribusi temperatur pada lapisan pertama lebih besar dibandingkan dengan lapisan kedua, hal ini disebabkan karena lapisan pertama konduktivitas panas nya lebih kecil dibandingkan konduktivitas panas pada lapisan kedua. Pernyataan ini sesuai dengan hukum Fourier tentang konduksi panas. 


\section{KESIMPULAN}

Pada tulisan ini telah dilakukan penyelesaian permasalahan syarat batas pada domain 2D. Permasalahan yang ditinjau adalah perpindahan panas konduksi dengan solusi berupa distribusi temperatur pada domain. Dari hasil yang diperoleh, didapatkan bahwa distribusi temperatur bergantung pada konduktivitas panas suatu bahan. Semakin besar konduktivitas panas maka distribusi temperatur semakin kecil hal ini bersesuaian dengan persamaan yang dijelaskan oleh Hukum Fourier. Distribusi temperatur juga berpengaruh pada sumber panas yang diberikan. Jika ada sumber panas yang diberikan maka distribusi temperatur menjadi meningkat dibandingkan domain yang tidak diberi sumber panas.

\section{DAFTAR PUSTAKA}

Birman, V., (1995), "Stability of Functionally Graded Hybrid Composite Plates”, Composites Eng., 5, hal. 913-921.

Birman, V., (1997), "Stability of Functionally Graded Shape Memory Alloy Sandwich Panels", Smart Mater. Struct., 6, hal. 278-286.

EL-Wazery, M. S. dan EL-Desouky, A. R., (2015), “A Review on Functionally Graded Ceramic-Metal Materials", Menoufiya University, Shebin ElKom, EGYPT, hal. 1369-1376.

Katili, I., 2006, Metode Elemen Hingga, Program UI, FEAP, FTUI, Depok.

Kreith, Frank, 1994, Prinsip-prinsip Perpindahan Panas, Arko Prijono (alih bahasa), Jakarta: Penerbit Erlangga.

Mas Irfan. P.H, dkk, (2014), "Meshless Local B-Spline-FD Method and its Application for 2D Heat Conduction Problems with Spatially Varying Thermal Conductivity", Applied Mathematics and Computation, 242, hal. 236-254.

Yunus, A. D., 2009, Perpindahan Panas dan Massa, Diktat Kuliah, Jurusan Teknik Mesin Fakultas Teknik Darma Persada, Jakarta.

Zienkiewicz, R. T., R. L. Taylor, and P. Nithiarasu, 2005, The Finite Element Method for Fluid Dynamics, $6^{\text {th }}$ ed., Elsevier Butterworth-Heinemann, Jordan Hill, Oxford. 